\title{
miR-149-5p inhibition reduces Alzheimer's disease $\beta$-amyloid generation in 293/APPsw cells by upregulating H4K16ac via KAT8
}

\author{
FUYAN CHEN $^{1,2}$, HUIFENG CHEN ${ }^{3}$, YUJIE JIA ${ }^{1}$, HAI LU $^{4}$, QIAORUI TAN ${ }^{4}$ and XIN ZHOU ${ }^{5}$ \\ ${ }^{1}$ Department of Acupuncture and Moxibustion, First Teaching Hospital of Tianjin University of Traditional Chinese Medicine; \\ ${ }^{2}$ National Clinical Research Center for Acupuncture and Moxibustion, Tianjin 300193; ${ }^{3}$ Department of Internal Neurology, \\ Tianjin Medical University General Hospital Airport Hospital, Tianjin 300308; ${ }^{4}$ Graduate School, \\ Tianjin University of Traditional Chinese Medicine; ${ }^{5}$ Department of Orthopedics, \\ First Teaching Hospital of Tianjin University of Traditional Chinese Medicine, Tianjin 300193, P.R. China
}

Received November 12, 2019; Accepted July 7, 2020

DOI: $10.3892 /$ etm.2020.9216

\begin{abstract}
Alzheimer's disease (AD), the leading cause of age-related dementia, is characterized by abnormal $\beta$-amyloid accumulation. During learning, memory formation and consolidation, increased levels of histone $\mathrm{H} 3$ and $\mathrm{H} 4$ acetylation are observed. The present study reported significantly decreased level of H4K16ac in the plasma of patients with AD compared with healthy subjects via western blotting and reverse transcription-quantitative (RT-q)PCR. Lysine acetyltransferase 8 (KAT8) expression, the major lysine acetyltransferase responsible for the acetylation of H4K16, was significantly decreased in patients with AD compared with healthy subjects as determined via western blotting and RT-qPCR. The results indicated that aberrant expression patterns of H4K16ac and KAT8 might be associated with AD progression. Moreover, western blot analysis demonstrated that KAT8-overexpression cells displayed increased levels of H4K16ac, accompanied by higher levels of neuroprotective soluble amyloid precursor protein (sAPP) $\alpha$ and $\beta$-secretase (BACE)2, and decreased levels of sAPP $\beta$ and BACE1 compared with negative control and vector cells. In neurodegenerative disorders, microRNAs (miRNAs/miRs) are deregulated; however, the effect of miRNA dysregulation on histone acetylation is not completely understood. To the best of our knowledge, the present study identified a novel inhibitory interaction between miR-149-5p and KAT8 3'-UTR that contributed to the pathological alterations in an AD cell model for the first time, using bioinformatics and a dual-luciferase reporter assay. The western blotting results indicated
\end{abstract}

Correspondence to: Professor Xin Zhou, Department of Orthopedics, First Teaching Hospital of Tianjin University of Traditional Chinese Medicine, 314 Anshan Xi Road, Nankai, Tianjin 300193, P.R. China

E-mail: fufhbb@126.com

Key words: Alzheimer's disease, microRNA-149-5p, histone acetylation, lysine acetyltransferase 8 that, compared with the inhibitor control group, miR-149-5p inhibitor markedly increased H4K16ac levels, which were significantly suppressed by co-transfection with KAT8 short hairpin (sh)RNA. KAT8 shRNA and miR-149-5p inhibitor co-transfection abolished the beneficial effects of miR-149-5p inhibitor. The results indicated that miR-149-5p regulated KAT8 and H4K16ac expression in an AD cell model, which may be associated with the pathological process of AD; therefore, miRNA may serve as a potential drug target for AD.

\section{Introduction}

Alzheimer's disease (AD), the most common cause of dementia in elderly individuals worldwide, is characterized by progressive memory and cognitive impairments (1). The abnormal accumulation of extracellular $\beta$-amyloid $(\mathrm{A} \beta)$ plaques in the brain is an important molecular pathological feature of patients with AD (2). A $\beta$ is produced by proteolytic cleavage of the amyloid precursor protein (APP) by $\beta$-secretases and $\gamma$-secretases $(3,4)$, which generates soluble (s)APP $\beta$, amyloid- $\beta_{1-40}\left(\mathrm{~A} \beta_{1-40}\right)$ and $A \beta_{1-42}$ fragments. The alternative proteolytic pathway of APP involves the release of $\alpha$-secretase, which prevents the formation of $A \beta$ due to its cleavage site and produces $\mathrm{SAPP} \alpha$ that serves as a neuroprotective player $(5,6)$.

MicroRNAs (miRNAs/miRs) are a class of endogenous 22-nucleotide non-coding RNAs that base-pair with the 3'-untranslated region (UTR) of specific genes, thereby repressing gene expression. Certain miRNAs serve as crucial players of neuronal gene expression that contribute to neurogenesis, neuronal maturation, brain development and neuroplasticity $(7,8)$. The involvement of miRNAs in the pathophysiology of AD has been demonstrated in a number of previous studies. For example, miR-15b inhibits $A \beta$ accumulation by targeting $\mathrm{NF}-\kappa \mathrm{B}$ signaling and $\beta$-secretase (BACE)1 (9). microRNA-219 downregulation promotes neurodegeneration via post-transcriptional regulation of microtubule associated protein tau (10). Recently, miR-149-5p was reported to protect against high glucose-induced pancreatic $\beta$-cell apoptosis (11). Furthermore, miR-149-5p was also revealed to regulate pentraxin resistance in breast cancer (12). However, 
the role of miR-149-5p in regulating APP and A $\beta$ production is not completely understood. Epigenetic dysregulation serves a vital role in the onset and progression of AD (13-21), which include chromatin variation, DNA methylation and non-coding RNAs (22). Among the widespread epigenetic modifications, histone acetylation and deacetylation are chromatin variations that regulate gene transcription (23). Histone acetylation is downregulated at regulatory regions of memory genes in mouse models of AD (24). Nonselective histone deacetylase inhibitor treatments were reported to improve memory impairments by restoring normal histone acetylation levels $(25,26)$. Among histone acetylation marks, H4K16ac facilitates gene activation and damaged DNA repair by influencing its chromatin structure (27). The largest meta-analytic genome-wide association study identified branched chain keto acid dehydrogenase kinase/KAT8 as a new AD-associated loci (28). KAT8 is the major lysine acetyl transferase responsible for the acetylation of H4K16 in flies and mammals (29). The present study compared serum histone acetylation and KAT8 in patients with AD and cognitively healthy individuals. In addition, the expression of miR-149-5p in an AD cell model in vitro was investigated, and the roles of miR-149-5p and its interaction with KAT8 in the AD cell model were also explored. Collectively, the results suggested that miR-149-5p levels were increased in patients with AD compared with healthy subjects, which regulated H4K16ac in 293/APPsw cells via targeting KAT8. Therefore, the present study indicated that targeting miR-149-5p may display neuroprotective effects in AD, suggesting that miR-149-5p may serve as a novel therapeutic target.

\section{Materials and methods}

Plasma analyses. Blood samples were obtained from patients with $\mathrm{AD}(\mathrm{n}=30)$ and healthy volunteers $(\mathrm{n}=30)$ with typical cognitive performance. Patients with AD were confirmed by screening cognitive impairment by conducting a Mini-Mental State Examination (patients with a score $\leq 24$ were included in the present study) and a neuropsychological test via Clinical Dementia Rating (an assay that can identify very mild dementia; dementia scale: 0 , none; 0.5 , very mild; 1 , mild; 2 , moderate; and 3 , severe) (30). All patients with AD had an overall CDR of $\geq 0.5$. Patients with AD were diagnosed according to NINCDS-ADRDA criteria (31). To further diagnose AD based on imaging-based techniques, the magnetic resonance image (MRI) relaxation time constant was examined in the brains of patients with $\mathrm{AD}$ according to a previous report (32). Neuropsychological impairment was measured according to the Global Deficit Score for classifying Neuropsychological impairment (33). All healthy subjects had no brain diseases, as assessed by MRI and computed tomography. In addition, healthy subjects did not have a history or symptoms of ischemic or hemorrhagic stroke. Exclusion criteria were as follows: i) history of any vascular or systemic disease; ii) any other neurodegenerative disease; iii) any psychiatric disease; iv) epilepsy; and v) substance or drug abuse. The present study was approved by the Institutional Ethics Committee of First Teaching Hospital of Tianjin University of Traditional Chinese Medicine (approval no. KY-E-2017-12-30). Written informed consent was obtained from all patients and healthy subjects.
Blood samples were collected in EDTA-containing tubes and processed within $2 \mathrm{~h}$. After collection, blood samples were centrifuged at $1,000 \mathrm{xg}$ for $10 \mathrm{~min}$ at $4^{\circ} \mathrm{C}$. Plasma was isolated and stored $1 \mathrm{ml}$ aliquots at $-80^{\circ} \mathrm{C}$ until further analysis.

Cell Culture. Human embryonic kidney (293) cells carrying the Swedish mutation of APP (293/APPsw), which were kindly provided by the Centre for Translational Medicine, Tianjin University of Traditional Chinese Medicine, were used in the present study. APPsw is an established AD cell model. Cells were cultured in DMEM/F-12 supplemented with 10\% FBS and $500 \mu \mathrm{g} / \mathrm{ml}$ G418 (all from Gibco; Thermo Fisher Scientific, Inc.) at $37^{\circ} \mathrm{C}$ in a humidified atmosphere of $5 \% \mathrm{CO}_{2}$.

Transfection. 293/APPsw cells were plated at $5 \times 10^{4}$ cells per well in a 24-well plate and transfected with $100 \mathrm{nM}$ miR-149-5p inhibitor, inhibitor negative control (inhibitor NC), short hairpin RNA (sh)-Scramble (sh-NC) orsh-KAT8, which were all purchased from GenePharma. Lipofectamine ${ }^{\circledR} 3000$ (Invitrogen; Thermo Fisher Scientific, Inc.) was used to transfect cells according to the manufacturer's protocol. Subsequent in vitro assays were performed 3 days post-transfection. Sequences of the oligonucleotides were as follows: miR-149-5p inhibitor: 5'-GGGAGUGAAGACACGGAGCCA GA-3' and inhibitor NC: 5'-CGAACGUGUCACGUTT-3. For stable KAT8 overexpression, at 50\% confluence, 293/APPsw cells were infected with purified lentiviral particles expressing KAT-8 (LV-KAT-8-puromycin; Shanghai GeneChem Co., Ltd.) or NC lentiviral particles (LV-puromycin; Shanghai GeneChem Co., Ltd.) at MOI=20. Subsequently, KAT8 overexpression cells were selected using puromycin for $72 \mathrm{~h}$ at $37^{\circ} \mathrm{C}$ in a humidified atmosphere of $5 \% \mathrm{CO}_{2}$. Reverse transcription-quantitative PCR and western blotting were performed to assess transfection efficiency.

ELISA assay. $\mathrm{A} \beta_{1-40}$ and $\mathrm{A} \beta_{1-42}$ levels in the cell medium were determined using a specific sandwich ELISA kit $\left(\mathrm{A} \beta_{1-40}\right.$, cat. no. MBS263658; A $\beta_{1-42}$, cat. no. MBS703888; both MyBioSource, Inc.) according to the manufacturer's protocol.

Western blotting. Total protein was extracted from cells using RIPA buffer (Beyotime Institute of Biotechnology). Protein concentration was determined using the Bicinchoninic Acid Protein Assay (Pierce; Thermo Fisher Scientific, Inc.). Equal amounts of protein $(20 \mu \mathrm{g} / \mathrm{lane})$ were separated via 8-12\% SDS-PAGE and transferred onto PVDF membranes (EMD Millipore). After blocking with 5\% skim milk in TBS for $2 \mathrm{~h}$ at room temperature, the membranes were incubated with the following primary antibodies at $4^{\circ} \mathrm{C}$ overnight: Anti-H3K4ac (Abcam; 1:500; cat. no. ab232931), anti-H3K27ac (Abcam; 1:500; cat. no. ab4729), anti-H4K12ac (EMD Millipore; 1:3,000, 04-119), anti-H4K16ac (EMD Millipore; 1:3,000; cat. no. 07-329), anti-APP (EMD Millipore; 1:1,500; cat. no. AB5300), anti-sAPP $\alpha$ (EMD Millipore; 1:1,000; cat. no. JP11088), anti-sAPP $\beta$ (EMD Millipore; 1:1,000; cat. no. MABN640), anti-BACE1 (Epitomics; 1:2,000; cat. no. ABCA0158537), anti-BACE2 (Epitomics; 1:2,000; cat. no. ABCA0157823) and anti-GAPDH (Santa Cruz Biotechnology, Inc.; 1:1,000; cat. no. sc-47724). After washing with TBST $(0.1 \%$ Tween 20$)$, the membranes were incubated 
with horseradish peroxidase-conjugated corresponding secondary antibodies (Santa Cruz Biotechnology, Inc.; 1:5,000; cat. no. sc-2357 for anti-rabbit IgG-HRP, and cat. no. sc-2005 for anti-mouse IgG-HRP) at $37^{\circ} \mathrm{C}$ for $1 \mathrm{~h}$. Protein bands were visualized using ECL substrate (Beyotime Institue of Biotechnology). Protein expression levels were semi-quantified using ImageJ software (v1.8.0, National Institutes of Health) with GAPDH (KAT8, APP, sAPP $\alpha$, sAPP $\beta$, BACE1 and BACE2) or $\mathrm{H} 3$ and $\mathrm{H} 4$ (H3K4ac, H3K27ac, H4K12ac and H4K16ac) as the loading controls $(30,31)$.

$R T-q P C R$. Total RNA was extracted from transfected 293/APPsw cells using TRIzol $^{\circledR}$ reagent (Invitrogen; Thermo Fisher Scientific, Inc.) following the manufacturer's protocol. Total RNA was reverse transcribed into cDNA using the PrimeScript ${ }^{\mathrm{TM}}$ RT reagent Kit (Takara Biomedical Technology (Beijing) Co., Ltd.), and the reverse transcription conditions were $37^{\circ} \mathrm{C}, 15 \mathrm{~min} ; 85^{\circ} \mathrm{C}, 5 \mathrm{sec}$. qPCR was performed using SYBR Premix Ex Taq kit (Takara Biomedical Technology Co., Ltd.) according to the manufacturer's instructions. The thermocycling conditions were $95^{\circ} \mathrm{C}$ for $10 \mathrm{~min}$ (initial denaturation) followed by 40 cycles of $95^{\circ} \mathrm{C}, 15 \mathrm{sec}$ (denaturation); $60^{\circ} \mathrm{C}, 1 \mathrm{~min}$ (annealing). The final stage was $95^{\circ} \mathrm{C}, 5 \mathrm{~min} ; 60^{\circ} \mathrm{C}, 1 \mathrm{~min} ; 95^{\circ} \mathrm{C}, 15 \mathrm{sec}$ for 1 cycle to obtain a dissolution curve. The following primers were used for qPCR: miR-149-5p forward, 5'-GGCTCTGGCTCCGTGTCTT-3' and reverse, 5'-CAGTGCAGGGTCCGAGGTATT-3'; KAT8 forward, 5'-GTCACGGTGGAGATCGGAGA-3' and reverse, 5'-CCCTCCTGGTCGTTCACTC-3'; U6 forward, 5'-GCTTCG GCAGCACATATACTAAAAT-3' and reverse, 5'-CGCTTC ACGAATTTGCGTGTCAT-3'; and GAPDH forward, 5'-GCC TTCCGTGTCCCCACTGC-3' and reverse, 5'-CAATGCCAG CCCCAGCGTCA-3'. miRNA and mRNA expression levels were quantified using the $2^{-\Delta \Delta C q}$ method (34) and normalized to the internal reference genes U6 and GAPDH, respectively.

Luciferase reporter assay. 293/APPsw cells ( $2 \times 10^{4}$ cells/well) were incubated in 24-well plates for $24 \mathrm{~h}$. Subsequently, cells were co-transfected with $50 \mathrm{ng}$ pGL3 luciferase vector carrying wild-type (WT) or mutated (MUT) 3'-UTR of KAT8 (Promega Corporation) and $50 \mathrm{nM}$ miR-149-5p-mimic or mimic-NC using Lipofectamine ${ }^{\circledR} 3000$ (Invitrogen; Thermo Fisher Scientific, Inc.). At $48 \mathrm{~h}$ post-transfection, luciferase activities were detected using a Dual-Luciferase Reporter Assay system (Guangzhou RiboBio Co., Ltd.) according to the manufacturer's instructions. Relative luciferase activity was normalized to Renilla luciferase activity.

Statistical analysis. All experiments were repeated at least three times independently. Data are presented as the mean \pm SEM. Statistical analyses were conducted using SPSS software (version 20.0; IBM Corp.). The figures and graphs were prepared using GraphPad Prism 7 (GraphPad Software, Inc.). The unpaired Student's t-test was used to compare two groups, and comparisons among multiple groups were analyzed using one-way ANOVA followed by Tukey's post hoc test. Pearson's correlation coefficient analysis was used to analyze the correlation between miR-149-5p and KAT8. $\mathrm{P}<0.05$ was considered to indicate a statistically significant difference.
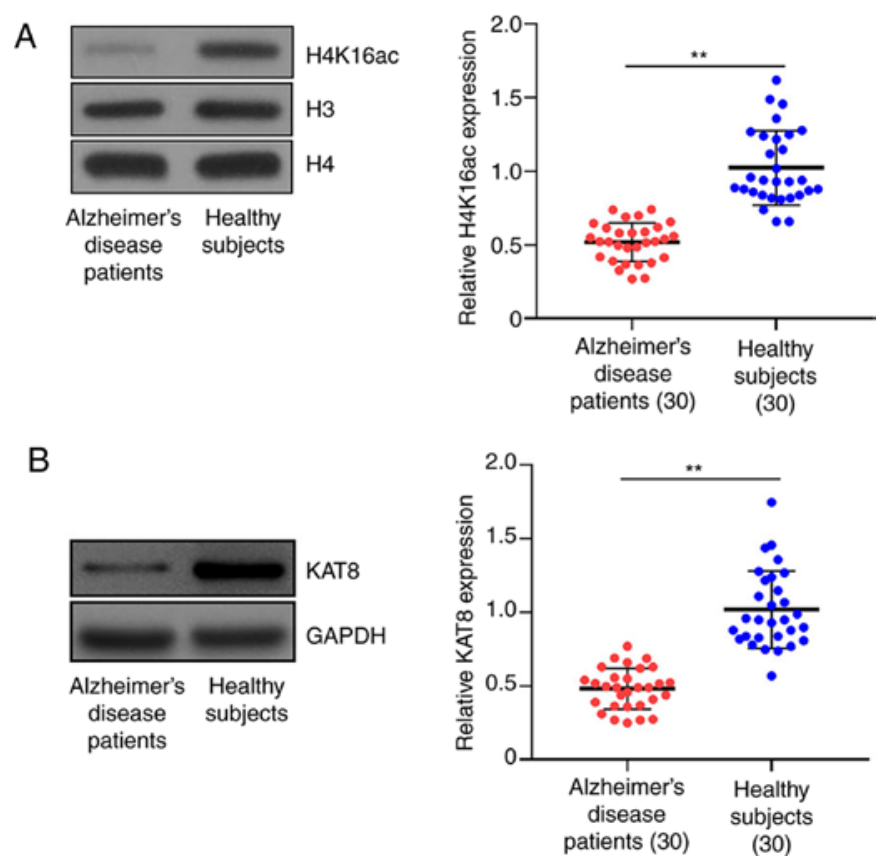

Figure 1. Aberrant expression of H4K16ac and KAT8 in the plasma of patients with AD. (A) H4K16ac and (B) KAT8 expression in the plasma of patients with $A D(n=30)$ and healthy subjects $(n-30) .{ }^{* *} \mathrm{P}<0.01$. KAT8, lysine acetyltransferase 8; AD, Alzheimer's disease.

\section{Results}

H4K16ac and KAT8 were downregulated in the plasma of patients with $A D$. First, primary acetylated histone protein (H3K4ac, H3K27ac, H4K12ac and H4K16ac) levels in the plasma of healthy subjects and patients with $\mathrm{AD}$ were analyzed via western blotting. Table I summarizes the characteristics of patients with $\mathrm{AD}$ and cognitively healthy volunteers. Although no difference was identified in H3K4ac and H3K27ac levels between healthy subjects and patients with AD, the H4K12ac level in patients with $\mathrm{AD}$ was notably downregulated compared with healthy subjects (Fig. S1). H4K16ac protein levels were notably decreased in patients with AD compared with healthy controls (Fig. 1A), which was further indicated at the mRNA level via RT-qPCR (Fig. 1A). The expression profile of KAT8, the major lysine acetyltransferase responsible for the acetylation of H4K16, was also evaluated. The RT-qPCR results demonstrated a reduction in KAT8 mRNA and protein expression in patients with AD compared with healthy subjects (Fig. 1B). Collectively, the results demonstrated that aberrant expression patterns of H4K16ac and KAT8 could be related to the progression of $\mathrm{AD}$.

KAT8 overexpression increases H4K16ac expression, reduces APP processing and decreases the $A \beta_{1-40} / A \beta 1_{-42}$ ratio in 293/APPsw cells. Histone-associated heterochromatin structural alterations are involved in the formation of long-term memory (35). Certain studies reported that increased levels of $\mathrm{H} 3$ and $\mathrm{H} 4$ acetylation are closely associated with memory consolidation $(36,37)$. In the present study, KAT8-overexpression 293/APPsw cells were constructed to explore the effect of KAT8 on the acetylation status of core histones in vitro. KAT8 mRNA and protein expression 
Table I. Characteristics of patients with AD and healthy subjects.

\begin{tabular}{|c|c|c|c|c|}
\hline Variable & $\begin{array}{l}\text { Patients with AD } \\
\qquad(\mathrm{n}=30)\end{array}$ & $\begin{array}{l}\text { Healthy subjects } \\
\qquad(\mathrm{n}=30)\end{array}$ & $\begin{array}{l}\text { Statistical } \\
\text { value }\end{array}$ & P-value \\
\hline Sex (male/female) & $17 / 13$ & $14 / 16$ & $0.601^{\mathrm{a}}$ & 0.438 \\
\hline Age (years) & $63.4 \pm 18.0$ & $64.1 \pm 16$ & $0.341^{\mathrm{b}}$ & 0.899 \\
\hline BMI $\left(\mathrm{kg} / \mathrm{m}^{2}\right)$ & $24.5 \pm 3.4$ & $24.7 \pm 4.4$ & $0.413^{\mathrm{b}}$ & 0.931 \\
\hline Diabetes/non-diabetes & $8 / 22$ & $5 / 25$ & $0.884^{\mathrm{a}}$ & 0.347 \\
\hline High blood pressure/normal blood pressure & $10 / 20$ & $7 / 23$ & $0.739^{\mathrm{a}}$ & 0.390 \\
\hline Coronary heart disease/non-coronary heart disease & $6 / 24$ & $3 / 27$ & $1.176^{\mathrm{a}}$ & 0.278 \\
\hline Smoker/non-smoker & $11 / 19$ & $10 / 20$ & $0.073^{\mathrm{a}}$ & 0.787 \\
\hline Drinker/non-drinker & $15 / 15$ & $16 / 14$ & $0.067^{\mathrm{a}}$ & 0.796 \\
\hline Educational years & $11.3 \pm 3.4$ & $11.7 \pm 3.7$ & $0.968^{\mathrm{b}}$ & 0.867 \\
\hline Left handed/right handed & $3 / 27$ & $5 / 25$ & $0.577^{\mathrm{a}}$ & 0.448 \\
\hline Duration of illness (years) & $8.5 \pm 4.7$ & - & - & - \\
\hline Pathological MRI (\%) & $75(60 \%)$ & - & - & - \\
\hline Neuropsychological impairment & $90(64 \%)$ & & & \\
\hline$(2 \mathrm{~T}$-scores $35 ; \%)(51,52)$ & & - & - & - \\
\hline MMSE scores & $18.9 \pm 3.6$ & $25.4 \pm 2.8$ & $5.65^{\mathrm{b}}$ & 0.001 \\
\hline \multicolumn{5}{|l|}{ CDR scale } \\
\hline CDR 0 & 0 & 30 & - & - \\
\hline CDR 0.5 & 7 & - & - & - \\
\hline CDR 1 & 11 & - & - & - \\
\hline $\mathrm{CDR} 2^{+}$ & 12 & - & - & - \\
\hline
\end{tabular}

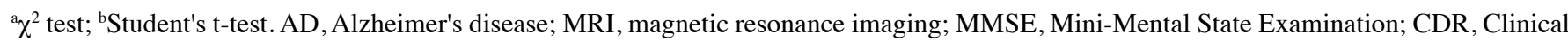
Dementia Rating; -, not applicable.

profiles were assessed via RT-qPCR and western blotting (Fig. 2A and B). Cellular H4K16ac was markedly higher in KAT8-overexpression 293/APPsw cells compared with NC and vector cells (Fig. 2C). Furthermore, cellular H4K12ac was slightly increased in KAT8-overexpression cells compared with NC and vector cells; however, there was no notable difference in $\mathrm{H} 3 \mathrm{~K} 4 \mathrm{ac}$ and $\mathrm{H} 3 \mathrm{~K} 27 \mathrm{ac}$ levels between KAT8-overexpression and control cells (Fig. S2). The results indicated that KAT8 overexpression in 293/APPsw cells induced H416K acetylation. Subsequently, the effects of KAT8 on APP processing in 293/APPsw cells were assessed. KAT8-overexpression 293/APPsw cells displayed markedly increased neuroprotective sAPP $\alpha$ expression levels, and decreased expression levels of sAPP $\beta$ and APP expression compared with NC and vector 293/APPsw cells (Fig. 2D). The $A \beta_{1-40} / A \beta_{1-42}$ ratio was significantly increased in KAT8-overexpression 293/APPsw cells compared with vector cells (Fig. 2E). The expression level of enzymes involved in proteolytic cleavage of APP, BACE1 (a key enzyme in sAPP $\beta$ generation) and BACE2 (a homolog of BACE1, which functions as an antagonist of BACE1 and blocks $A \beta$ production), were assessed $(38,39)$. The western blotting results indicated that BACE2 expression was markedly upregulated in KAT8-overexpression cells compared with $\mathrm{NC}$ and vector cells. Likewise, BACE1 expression was downregulated in KAT8-overexpression cells compared with $\mathrm{NC}$ and vector cells (Fig. 2D), which suggested that KAT8 was associated with the proteolytic processing of APP protein.
KAT8 is a direct target of miR-149-5p. Since miRNAs inhibit transcription of specific mRNAs by binding to their 3'-UTRs (40), starBase (version 2.0, http://starbase.sysu. edu.cn/starbase $2 /$ ) computational analyses were conducted to predict potential miRNA interactions in the 3'-UTR of KAT8. A putative miR-149-5p target site in the 3'-UTR of KAT8 was identified (Fig. 3A). To validate the interaction between miR-149-5p and KAT8, a luciferase reporter assay was conducted. The luciferase activity of 293/APPsw cells co-transfected with miR-149-5p mimic and WT 3'-UTR was significantly reduced compared with cells co-transfected with miR-NC and WT 3'UTR (Fig. 3B); however, the luciferase activity was not significantly different between cells co-transfected with miR-149-5p mimic and MUT 3'-UTR, and cells co-transfected with miR-NC and MUT 3'-UTR (Fig. 3B). The results suggested that KAT8 may serve as a potential target of miR-149-5p. Since miRNAs can circulate in the blood and cerebrospinal fluid, they have been identified as biomarkers of various diseases, including AD (41). Subsequently, the expression of miR-149-5p in the plasma of patients with AD and healthy controls was assessed. miR-149-5p expression levels were significantly upregulated in the plasma of patients with AD compared with healthy subjects (Fig. 3C). Pearson's correlation coefficient analysis revealed a negative linear correlation between the expression level of miR-149-5p and KAT8 (Fig. 3D), which further indicated that KAT8 may serve as a potential target of miR-149-5p. To further clarify the negative relationship between miR-149-5p and KAT8, miR-149-5p 


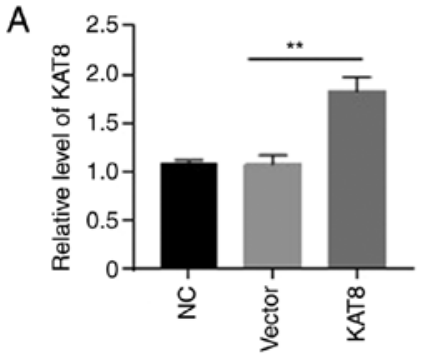

B

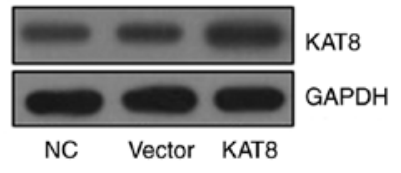

C

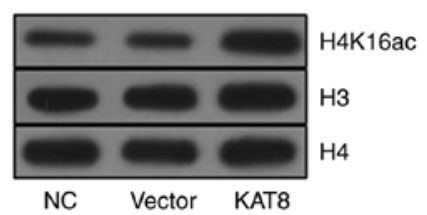

$\mathrm{D}$

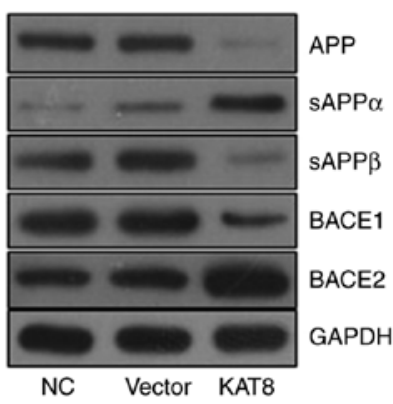

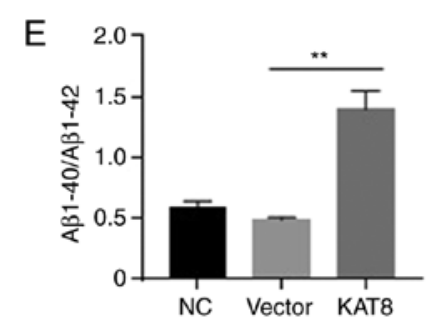

Figure 2. KAT8 overexpression increases H4K16 acetylation, inhibits amyloidogenic APP processing and reduces the A $\beta_{1-40} / \mathrm{A} \beta_{1-42}$ ratio. KAT8 (A) mRNA and (B) protein expression levels in KAT8-overexpression 293/APPsw cells. (C) H4K16ac expression in KAT8-overexpression 293/APPsw cells. (D) KAT8 overexpression reduces protein expression levels of amyloidogenic APP, sAPP $\beta$ and BACE1, and increases neuroprotective sAPP $\alpha$ and BACE2 expression levels. (E) KAT8 overexpression reduces the $\mathrm{A} \beta_{1-40} / \mathrm{A} \beta_{1-42}$ ratio. ${ }^{* *} \mathrm{P}<0.01$. KAT8, lysine acetyltransferase 8; APP, amyloid precursor protein; sAPP, soluble APP; $\mathrm{A} \beta, \beta$-amyloid; BACE, $\beta$-secretase; NC, negative control.

A

$\begin{aligned} & \text { KAT8 mutation (KAT8 3' UTR) } \\ \text { KAT8-WT } & 5^{\prime} \text { agcccaGAGGA--GGGCAGCCAGc } \\ \text { II II I I I I I I I I I I I I } & \text { 3' cccucaCUUCUGUGCCUCGGUCu } \\ \text { miR-149-5p } & \\ \text { KAT8-MUT } & \text { 5' agcccaCGGCC--GGACCAGAAGc }\end{aligned}$
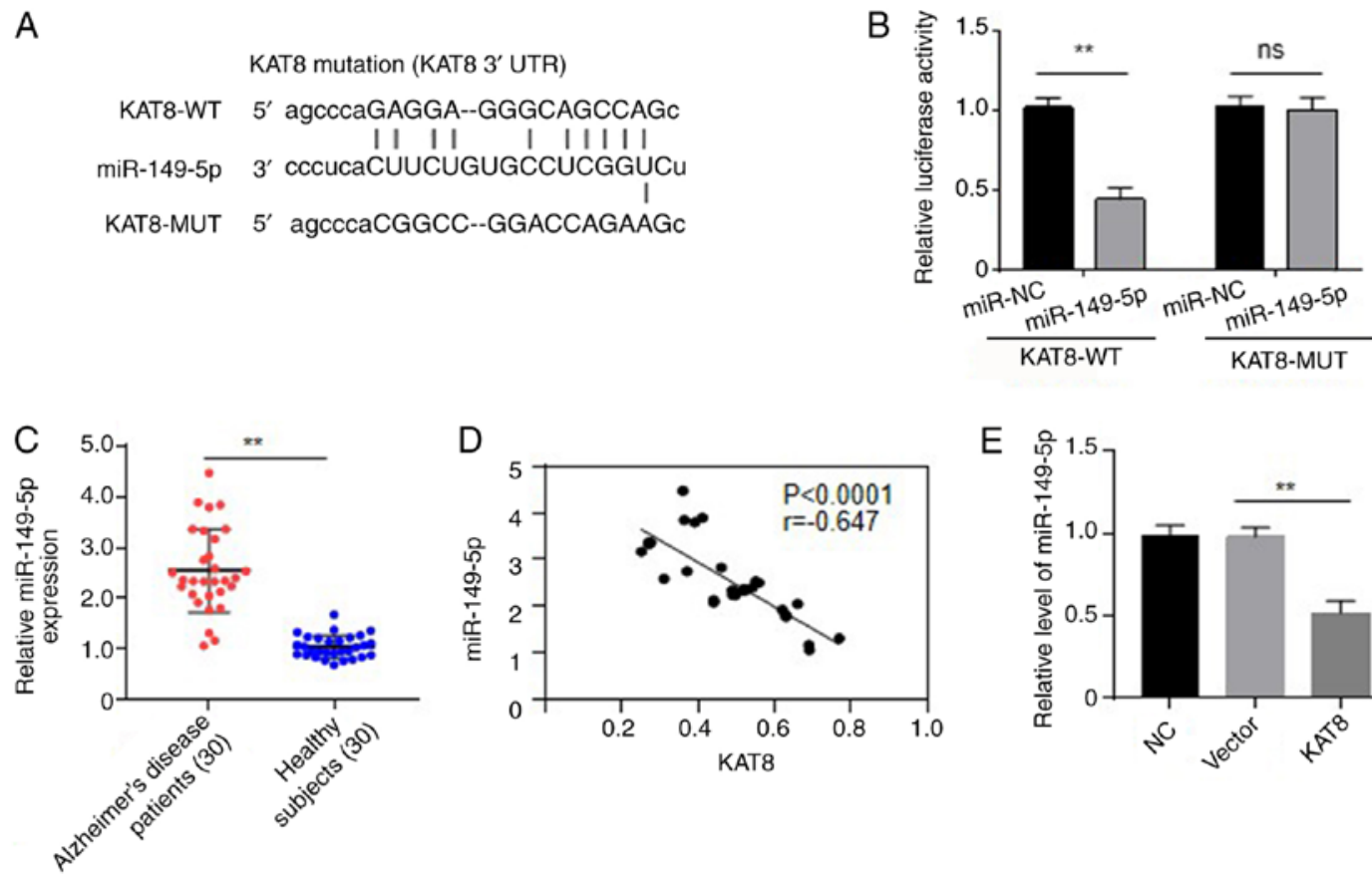

Figure 3. KAT8 is a direct target of miR-149-5p. (A) The binding site between KAT8 and miR-149-5p. (B) Luciferase activity in 293/APPsw cells co-transfected with KAT8-WT or KAT8-MUT and miR-NC or miR-149-5p mimic, ${ }^{* *} \mathrm{P}<0.01$ compared with miR-NC group. (C) miR-149-5p expression level in the plasma of patients with $\mathrm{AD}(\mathrm{n}=30)$ compared with healthy subjects $(\mathrm{n}=30)$. (D) Pearson's correlation coefficient analysis identified a negative correlation between serum miR-149-5p and KAT8 in patients with AD. (E) Effect of KAT8 overexpression on miR-149-5p expression. * P $<0.01$. KAT8, lysine acetyltransferase 8; miR, microRNA; WT, wild-type; MUT, mutated; NC, negative control; AD, Alzheimer's disease; UTR, untranslated region; ns, not significant.

expression was assessed in KAT8-overexpression 293/APPsw cells. The RT-qPCR results suggested that miR-149-5p expression was significantly decreased in KAT8-overexpression cells compared with vector control cells (Fig. 3E). Collectively, the results indicated that KAT8 may serve as a potential target of miR-149-5p.
miR-149-5p negatively regulates H4K16ac and promotes amyloid pathology by targeting KAT8 in 293/APPsw cells. To explore the effect of miR-149-5p on the pathological alterations associated with KAT8 in patients with $\mathrm{AD}$, the levels of H416Kac, sAPP $\alpha$, sAPP $\beta$, BACE1 and BACE2 were assessed following KAT8 knockdown and co-transfection with 
A

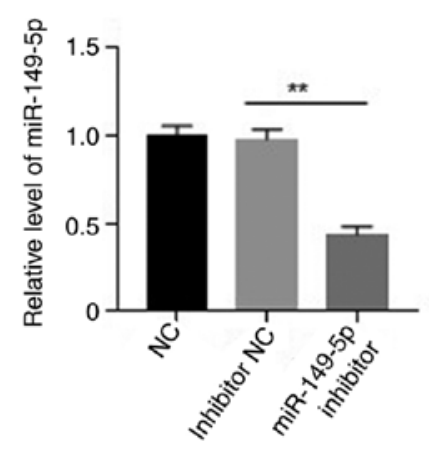

D
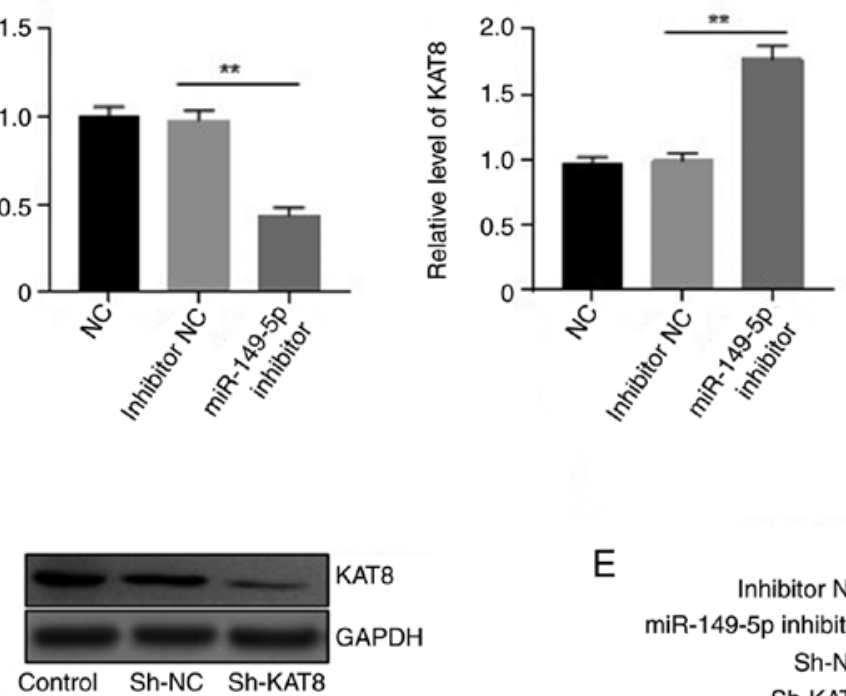
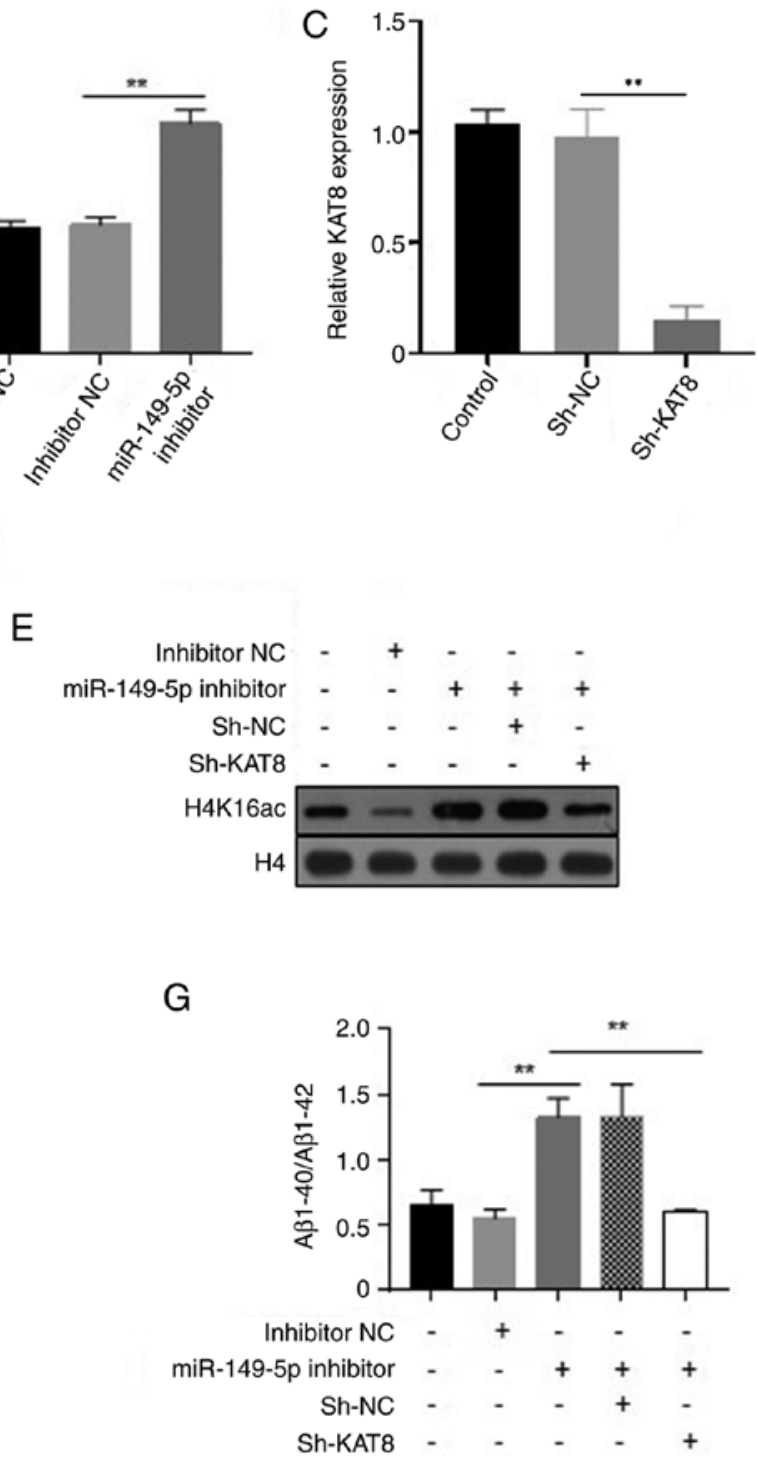

Figure 4. miR-149-5p inhibition exhibits neuroprotective properties in 293/APPsw cells, which are blocked by KAT8 knockdown. (A) Transfection efficiency of miR-149-5p inhibitor. (B) Effect of miR-149-5p inhibitor on KAT8 expression. Transfection efficiency of sh-KAT8 as determined by (C) reverse transcription-quantitative PCR and (D) western blotting. (E) Effect of miR-149-5p inhibitor and sh-KAT8 on H4K16ac, (F) APP, sAPP $\alpha$, sAPP $\beta$, BACE1, BACE2 and (G) the ratio of $A \beta 1-40 / A \beta 1-42 .{ }^{* *} \mathrm{P}<0.01$. miR, microRNA; KAT8, lysine acetyltransferase 8; sh, short hairpin RNA; APP, amyloid precursor protein; sAPP, soluble APP; BACE, $\beta$-secretase; A $\beta, \beta$-amyloid; NC, negative control.

miR-149-5p inhibitor in 293/APPsw cells. miR-149-5p inhibitor significantly decreased miR-149-5p expression and increased KAT8 mRNA expression in 293/APPsw cells compared with the inhibitor NC group (Fig. 4A and B). The results indicated that exogenous miR-149-5p may inhibit KAT8 expression via mRNA destabilization. Based on the finding that KAT8 promoted H4K16 acetylation, whether KAT8 knockdown and co-transfection with miR-149-5p inhibitor altered H4K16ac levels was investigated. The knockdown efficacy of sh-KAT8 was assessed (Fig. 4C and D). Compared with the inhibitor NC group, the western blotting results indicated that miR-149-5p inhibitor markedly increased H4K16ac levels, which were notably suppressed by co-transfection with KAT8 shRNA. miR-149-5p inhibitor markedly reduced sAPP $\beta$ and BACE1 expression levels, increased sAPP $\alpha$ and BACE2 expression levels, and increased the $A \beta_{1-40} / A \beta_{1-42}$ ratio compared with the inhibitor NC group. Moreover, co-transfection of sh-KAT8 and miR-149-5p inhibitor reversed miR-149-5p inhibitor-mediated effects, resulting in increased levels of sAPP $\beta$ and BACE1, and a decreased $A \beta_{1-40} / A \beta_{1-42}$ ratio, but reduced $A P P \alpha$ and BACE2 production (Fig. 4F and G). In summary, the results indicated that inhibiting miR-149-5p delivery could promote amyloidogenic APP processing and decrease the $A \beta_{1-40} / A \beta_{1-42}$ ratio by upregulating KAT8 and H4K16ac expression.

\section{Discussion}

Several reports indicated that histone acetylation, one of the main epigenetic modifications, could contribute to AD onset and progression $(17,19,42)$. The present study compared acetylation of several core histones in the plasma of patients with AD and cognitively healthy individuals. H4K16ac was significantly downregulated in the plasma of patients with AD compared with healthy subjects. In addition, KAT8 expression levels, the major lysine acetyltransferase responsible for the acetylation of H4K16 in flies and mammals (29), were 
decreased in patients with AD compared with healthy subjects, which implied that aberrant expression patterns of H4K16ac and KAT8 could be related to the progression of AD. AD is a multifactorial neurodegenerative disease, and the abnormal deposition of $A \beta$ is a critical feature of the disease (43). The present study indicated that KAT8 overexpression increased the level of H4K16ac in 293/APPsw cells compared with the $\mathrm{NC}$ and vector groups. Moreover, compared with the $\mathrm{NC}$ and vector groups, KAT8 overexpression also increased expression levels of neuroprotective sAPP $\alpha$ and BACE2, and significantly decreased the levels of neurotoxic SAPP $\beta$ and BACE1, which suggested that KAT8 may serve as a critical player in APP processing via regulating acetylation of core histones.

Specific miRNAs have been reported to participate during the initiation and progression of $\mathrm{AD}(9,44,45)$; however, the effect of miRNAs on histone acetylation and deacetylation during AD development is not completely understood. To the best of our knowledge, for the first time, the present study identified a novel inhibitory interaction between miR-149-5p and KAT8 3'-UTR that participated in the pathological alterations of an AD cell model via regulation of H416Kac levels. Numerous dysregulated miRNAs such as miR-223 (46), miR-455-3p (47), and miR-16 (48) were reported among patients with $\mathrm{AD}$, animal AD models and AD model cell lines, which served an essential role in amyloidogenic APP processing, synaptic dysfunction and other pathophysiological processes of AD. Although previous studies revealed that miR-149-5p is involved in cell migration, proliferation, apoptosis and major signaling pathways in various cell carcinomas $(49,50)$, the expression profile of miR-149-5p in AD has not been previously reported. The present study indicated that miR-149-5p was significantly increased in the plasma of patients with AD and the AD cell model compared with healthy subjects, and $\mathrm{NC}$ and vector cells, respectively. Additionally, the dual-luciferase reporter assay indicated a negative relationship between miR-149-5p and KAT8 in the plasma of patients with AD, which might promote AD pathogenesis via regulating KAT8 expression levels. Furthermore, miR-149-5p displayed neurotoxic effects on 293/APPsw cells, as indicated by miR-149-5p inhibitor reducing APP and A $\beta$ levels in 293/APPsw cells via regulating KAT8 expression and H4K16 acetylation.

The present study suggested that miR-149-5p could negatively regulate KAT8 and H4K16ac in vitro. Since histone acetylation serves a critical role in learning and memory consolidation (37), the present study revealed that KAT8 overexpression increased H4K16 acetylation compared with the NC and vector groups. KAT8-induced increases in H4K16 acetylation altered histone-associated heterochromatin structures, which could regulate a variety of AD-related gene transcriptions and suppress neurotoxic APP processing. The effect of miR-149-5p knockdown on KAT8 expression and $\mathrm{A} \beta$ formation requires further investigation. In conclusion, the present study suggested a potential novel approach to attenuate the pathological progression of AD by reducing miR-149-5p expression.

The present study had a key limitation; 293 cells carrying the Swedish mutation of APP (293/APPsw) were used as an established AD cell model. However, 293 cells lacking the Swedish mutation of APP were not used as a control group to evaluate whether the inhibitory effect of miR-149-5p on amyloid- $\beta$ generation was due to the APPsw mutation. Therefore, future studies should use 293 cells lacking the Swedish mutation of APP as a control group to verify the results of the present study.

\section{Acknowledgements}

Not applicable.

\section{Funding}

The present study was supported by the National Natural Science Foundation of China (grant nos. 81603684 and 81603686).

\section{Availability of data and materials}

The datasets used and/or analyzed during the current study are available from the corresponding author on reasonable request.

\section{Authors' contributions}

FC contributed to designing the study, and collecting, analyzing and interpreting the data. FC, HC, YJ, HL and QT contributed to collecting the data, drafting the manuscript and performing the literature search. XZ contributed to designing the study and drafting the manuscript. All authors read and approved the final version of the manuscript and agree to be accountable for all aspects of the research in ensuring that the accuracy or integrity of any part of the work are appropriately investigated and resolved.

\section{Ethics approval and consent to participate}

The present study was approved by the Ethics Committee of First Teaching Hospital of Tianjin University of Traditional Chinese Medicine. Written informed consent was obtained from all patients and healthy subjects.

\section{Patient consent for publication}

Not applicable.

\section{Competing interests}

The authors declare that they have no competing interests.

\section{References}

1. Nelson PT, Braak H and Markesbery WR: Neuropathology and cognitive impairment in Alzheimer disease: A complex but coherent relationship. J Neuropathol Exp Neurol 68: 1-14, 2009.

2. Gouras GK, Olsson TT and Hansson O: $\beta$-Amyloid peptides and amyloid plaques in Alzheimer's disease. Neurotherapeutics 12: 3-11, 2015 .

3. Hussain I, Powell D, Howlett DR, Tew DG, Meek TD, Chapman C, Gloger IS, Murphy KE, Southan CD, Ryan DM, et al: Identification of a novel aspartic protease (Asp 2) as beta-secretase. Mol Cell Neurosci 14: 419-427, 1999.

4. Yan R, Bienkowski MJ, Shuck ME, Miao H, Tory MC, Pauley AM, Brashier JR, Stratman NC, Mathews WR, Buhl AE, et al: Membrane-anchored aspartyl protease with Alzheimer's disease beta-secretase activity. Nature 402: 533-537, 1999. 
5. Ourdev D, Foroutanpay BV, Wang Y and Kar S: The effect of A $\beta 1-42$ oligomers on APP processing and A $\beta 1-40$ generation in cultured U-373 astrocytes. Neurodegener Dis 15: 361-368, 2015.

6. Zhang YW, Thompson $\mathrm{R}$, Zhang $\mathrm{H}$ and $\mathrm{Xu} \mathrm{H}$ : APP processing in Alzheimer's disease. Mol Brain 4: 3, 2011.

7. Kapsimali M, Kloosterman WP, de Bruijn E, Rosa F, Plasterk RH and Wilson SW: MicroRNAs show a wide diversity of expression profiles in the developing and mature central nervous system. Genome Biol 8: R173, 2007.

8. Konopka W, Kiryk A, Novak M, Herwerth M, Parkitna JR, Wawrzyniak M, Kowarsch A, Michaluk P, Dzwonek J, Arnsperger T, et al: MicroRNA loss enhances learning and memory in mice. J Neurosci 30: 14835-14842, 2010.

9. Li J and Wang $\mathrm{H}$ : miR-15b reduces amyloid- $\beta$ accumulation in SH-SY5Y cell line through targetting NF- $\kappa \mathrm{B}$ signaling and BACE1. Biosci Rep 38: BSR20180051, 2018.

10. Santa-Maria I, Alaniz ME, Renwick N, Cela C, Fulga TA Van Vactor D, Tuschl T, Clark LN, Shelanski ML, McCabe BD and Crary JF: Dysregulation of microRNA-219 promotes neurodegeneration through post-transcriptional regulation of tau J Clin Invest 125: 681-686, 2015.

11. Ruan D, Liu Y, Wang X, Yang D and Sun Y: miR-149-5p protects against high glucose-induced pancreatic beta cell apoptosis via targeting the BH3-only protein BIM. Exp Mol Pathol 110: 104279, 2019.

12. Xiang F, Fan Y, Ni Z, Liu Q, Zhu Z, Chen Z, Hao W, Yue H, Wu R and Kang X: Ursolic acid reverses the chemoresistance of breas cancer cells to paclitaxel by targeting miRNA-149-5p/MyD88. Front Oncol 9: 501, 2019.

13. Lu H, Liu X, Deng Y and Qing H: DNA methylation, a hand behind neurodegenerative diseases. Front Aging Neurosci 5: 85, 2013.

14. Mastroeni D, Grover A, Delvaux E, Whiteside C, Coleman PD and Rogers J: Epigenetic mechanisms in Alzheimer's disease. Neurobiol Aging 32: 1161-1180, 2011.

15. Aubry S, Shin W, Crary JF, Lefort R, Qureshi YH, Lefebvre C, Califano A and Shelanski ML: Assembly and interrogation of Alzheimer's disease genetic networks reveal novel regulators of progression. PLoS One 10: e0120352, 2015.

16. Min SW, Cho SH, Zhou Y, Schroeder S, Haroutunian V, Seeley WW, Huang EJ, Shen Y, Masliah E, Mukherjee C, et al: Acetylation of tau inhibits its degradation and contributes to tauopathy. Neuron 67: 953-966, 2010.

17. Lu X, Deng Y, Yu D, Cao H, Wang L, Liu L, Yu C, Zhang Y, Guo X and Yu G: Histone acetyltransferase p300 mediates histone acetylation of PS1 and BACE1 in a cellular model of Alzheimer's disease. PLoS One 9: e103067, 2014.

18. Marques SC, Lemos R, Ferreiro E, Martins M, de Mendonça A Santana I, Outeiro TF and Pereira CM: Epigenetic regulation of BACE1 in Alzheimer's disease patients and in transgenic mice. Neuroscience 220: 256-266, 2012.

19. Peleg S, Sananbenesi F, Zovoilis A, Burkhardt S, Bahari-Javan S, Agis-Balboa RC, Cota P, Wittnam JL, Gogol-Doering A, Opitz L, et al: Altered histone acetylation is associated with age-dependent memory impairment in mice. Science 328 753-756, 2010

20. Walker MP, LaFerla FM, Oddo SS and Brewer GJ: Reversible epigenetic histone modifications and Bdnf expression in neurons with aging and from a mouse model of Alzheimer's disease. Age (Dordr) 35: 519-531, 2013.

21. Lau P, Frigerio CS and De Strooper B: Variance in the identification of microRNAs deregulated in Alzheimer's disease and possible role of lincRNAs in the pathology: The need of larger datasets. Ageing Res Rev 17: 43-53, 2014

22. Goldberg AD, Allis CD and Bernstein E: Epigenetics: A landscape takes shape. Cell 128: 635-638, 2007.

23. Kouzarides T: Chromatin modifications and their function. Cell 128: 693-705, 2007.

24. Yamakawa H, Cheng J, Penney J, Gao F, Rueda R, Wang J, Yamakawa S, Kritskiy O, Gjoneska E and Tsai LH: The transcription factor $\mathrm{Sp} 3$ cooperates with HDAC2 to regulate synaptic function and plasticity in neurons. Cell Rep 20 1319-1334, 2017.

25. Chuang DM, Leng Y, Marinova Z, Kim HJ and Chiu CT: Multiple roles of HDAC inhibition in neurodegenerative conditions. Trends Neurosci 32: 591-601, 2009.

26. Gräff $\mathbf{J}$ and Mansuy IM: Epigenetic dysregulation in cognitive disorders. Eur J Neurosci 30: 1-8, 2009.
27. Sharma GG, So S, Gupta A, Kumar R, Cayrou C, Avvakumov N, Bhadra U, Pandita RK, Porteus MH, Chen DJ, et al: MOF and histone $\mathrm{H} 4$ acetylation at lysine 16 are critical for DNA damage response and double-strand break repair. Mol Cell Biol 30: 3582-3595, 2010.

28. Marioni RE, Harris SE, Zhang Q, McRae AF, Hagenaars SP, Hill WD, Davies G, Ritchie CW, Gale CR, Starr JM, et al: GWAS on family history of Alzheimer's disease. Transl Psychiatry 8: 99, 2018.

29. Chatterjee A, Seyfferth J, Lucci J, Gilsbach R, Preissl S, Böttinger L, Mårtensson CU, Panhale A, Stehle T, Kretz O, et al: MOF acetyl transferase regulates transcription and respiration in mitochondria. Cell 167: 722-738 e723, 2016.

30. Guo R, Fan G, Zhang J, Wu C, Du Y, Ye H, Li Z, Wang L, Zhang Z, Zhang L, et al: A 9-microRNA signature in serum serves as a noninvasive biomarker in early diagnosis of Alzheimer's disease. J Alzheimers Dis 60: 1365-1377, 2017.

31. Tamaoka A: Alzheimer's disease: Definition and national institute of neurological and communicative disorders and stroke and the Alzheimer's disease and related disorders association (NINCDS-ADRDA). Nihon Rinsho 2 (Suppl 69): S240-S245, 2011 (In Japanese)

32. Haris M, Singh A, Cai K, McArdle E, Fenty M, Davatzikos C, Trojanowski JQ, Melhem ER, Clark CM and Borthakur A: $\mathrm{T}(1 \mathrm{p}) \mathrm{MRI}$ in Alzheimer's disease: Detection of pathological changes in medial temporal lobe. J Neuroimaging 21: e86-e90, 2011.

33. Reichenberg A, Harvey PD, Bowie CR, Mojtabai R, Rabinowitz J, Heaton RK and Bromet E: Neuropsychological function and dysfunction in schizophrenia and psychotic affective disorders. Schizophr Bull 35: 1022-1029, 2009.

34. Livak KJ and Schmittgen TD: Analysis of relative gene expression data using real-time quantitative PCR and the 2(-Delta Delta C(T)) method. Methods 25: 402-408, 2001.

35. Mews P, Donahue G, Drake AM, Luczak V, Abel T and Berger SL: Acetyl-CoA synthetase regulates histone acetylation and hippocampal memory. Nature 546: 381-386, 2017.

36. Gräff J and Tsai LH: The potential of HDAC inhibitors as cognitive enhancers. Annu Rev Pharmacol Toxicol 53: 311-330, 2013.

37. Levenson JM, O'Riordan KJ, Brown KD, Trinh MA, Molfese DL and Sweatt JD: Regulation of histone acetylation during memory formation in the hippocampus. J Biol Chem 279: 40545-40559, 2004.

38. Basi G, Frigon N, Barbour R, Doan T, Gordon G, McConlogue L, Sinha S and Zeller M: Antagonistic effects of beta-site amyloid precursor protein-cleaving enzymes 1 and 2 on beta-amyloid peptide production in cells. J Biol Chem 278: 31512-31520, 2003.

39. Sun X, He G and Song W: BACE2, as a novel APP theta-secretase, is not responsible for the pathogenesis of Alzheimer's disease in down syndrome. FASEB J 20: 1369-1376, 2006.

40. Lu TX and Rothenberg ME: MicroRNA. J Allergy Clin Immunol 141: 1202-1207, 2018.

41. Zetterberg $\mathrm{H}$ and Burnham SC: Blood-based molecular biomarkers for Alzheimer's disease. Mol Brain 12: 26, 2019.

42. Gräff J, Rei D, Guan JS, Wang WY, Seo J, Hennig KM, Nieland TJF, Fass DM, Kao PF, Kahn M, et al: An epigenetic blockade of cognitive functions in the neurodegenerating brain. Nature 483: 222-226, 2012

43. Dorszewska J, Prendecki M, Oczkowska A, Dezor M and Kozubski W: Molecular basis of familial and sporadic Alzheimer's disease. Curr Alzheimer Res 13: 952-963, 2016.

44. Wang L, Liu J, Wang Q, Jiang H, Zeng L, Li Z and Liu R: MicroRNA-200a-3p mediates neuroprotection in Alzheimer-related deficits and attenuates amyloid-beta overproduction and tau hyperphosphorylation via coregulating BACE1 and PRKACB. Front Pharmacol 10: 806, 2019.

45. Long JM, Ray B and Lahiri DK: MicroRNA-339-5p down-regulates protein expression of $\beta$-site amyloid precursor protein-cleaving enzyme 1 (BACE1) in human primary brain cultures and is reduced in brain tissue specimens of Alzheimer disease subjects. J Biol Chem 289: 5184-5198, 2014.

46. Jia LH and Liu YN: Downregulated serum miR-223 servers as biomarker in Alzheimer's disease. Cell Biochem Funct 34: 233-237, 2016.

47. Kumar S, Vijayan M and Reddy PH: MicroRNA-455-3p as a potential peripheral biomarker for Alzheimer's disease. Hum Mol Genet 26: 3808-3822, 2017. 
48. Zhang B, Chen CF, Wang AH and Lin QF: miR-16 regulates cell death in Alzheimer's disease by targeting amyloid precursor protein. Eur Rev Med Pharmacol Sci 19: 4020-4027, 2015.

49. Chen W, Zhang J, Xu H, Dai J and Zhang X: The negative regulation of miR-149-5p in melanoma cell survival and apoptosis by targeting LRIG2. Am J Transl Res 9: 4331-4340, 2017.

50. Xu RD, Feng F, Yu XS, Liu ZD and Lao LF: miR-149-5p inhibits cell growth by regulating TWEAK/Fn14/PI3K/AKT pathway and predicts favorable survival in human osteosarcoma. Int J Immunopathol Pharmacol 32: 2058738418786656 , 2018.

51. Sundermann EE, Heaton RK, Pasipanodya E, Moore RC, Paolillo EW, Rubin LH, Ellis R, Moore DJ and Group HNRP: Sex differences in HIV-associated cognitive impairment. AIDS 32: 2719-2726, 2018
52. Norman MA, Moore DJ, Taylor M, Franklin D Jr, Cysique L, Ake C, Lazarretto D, Vaida F, Heaton RK and Group HNRC: Demographically corrected norms for African Americans and caucasians on the hopkins verbal learning test-revised, brief visuospatial memory test-revised, stroop color and word test, and wisconsin card sorting test 64-card version. J Clin Exp Neuropsychol 33: 793-804, 2011.

(i) (9) This work is licensed under a Creative Commons Attribution-NonCommercial-NoDerivatives 4.0 International (CC BY-NC-ND 4.0) License. 